\title{
Safety of perioperative hyperthermic intraperitoneal chemotherapy with gemcitabine in patients with resected pancreatic adenocarcinoma: a pilot study of the clinical trial EudraCT 2016-004298-41
}

\author{
David Padilla-Valverde ${ }^{1}$, Esther García-Santos ${ }^{1}$, Susana Sanchez ${ }^{1}$, Carmen Manzanares ${ }^{1}$, \\ Marta Rodriguez ${ }^{2}$, Lucia González ${ }^{3}$, Alfonso Ambrós ${ }^{4}$, Juana M. Cano ${ }^{5}$, Leticia Serrano ${ }^{6}$, \\ Raquel Bodoque $^{6}$, Teresa Vergara ${ }^{1}$, Jesus Martin ${ }^{1}$
}

${ }^{1}$ Department of Surgery, University General Hospital, Ciudad Real, Faculty of Medicine, Ciudad Real, University of Castilla-La Mancha, Castilla La Mancha, Spain; ${ }^{2}$ Department of Pharmacy, University General Hospital, Ciudad Real, Faculty of Medicine, Ciudad Real, University of CastillaLa Mancha, Castilla La Mancha, Spain; ${ }^{3}$ Department of Pathology, University General Hospital, Ciudad Real, Faculty of Medicine, Ciudad Real, University of Castilla-La Mancha, Castilla La Mancha, Spain; ${ }^{4}$ Intensive Care Unit, University General Hospital, Ciudad Real, Faculty of Medicine, Ciudad Real, University of Castilla-La Mancha, Castilla La Mancha, Spain; ${ }^{5}$ Department of Oncology, University General Hospital, Ciudad Real, Faculty of Medicine, Ciudad Real, University of Castilla-La Mancha, Castilla La Mancha, Spain; ${ }^{6}$ Translational Investigation Unit, UIT, University General Hospital, Ciudad Real, Faculty of Medicine, Ciudad Real, University of Castilla-La Mancha, Castilla La Mancha, Spain

Contributions: (I) Conception and design: D Padilla-Valverde, E García-Santos, S Sanchez; (II) Administrative support: D Padilla-Valverde, J Martín, A Ambros; (III) Provision of study material or patients: D Padilla-Valverde, M Rodriguez, L Gonzalez, JM Cano; (IV) Collection and assembly of data: D Padilla-Valverde, E García-Santos, S Sanchez, C Manzanares, T Vergara; (V) Data analysis and interpretation: D Padilla-Valverde, L Serrano, R Bodoque, T Vergara; (VI) Manuscript writing: All authors; (VII) Final approval of manuscript: All authors.

Correspondence to: David Padilla-Valverde, MD, PhD. Chief of Hepatobiliary Surgical Unit and Carcinomatosis Program, Department of Surgery, University General Hospital, Ciudad Real, Faculty of Medicine, Ciudad Real, University of Castilla-La Mancha, Castilla La Mancha, Spain.

Email: marcote15@yahoo.es.

Background: Hyperthermic intraperitoneal chemotherapy (HIPEC) with gemcitabine, after cytoreductive surgery, may reduce the tumor progression of pancreatic cancer through the reduction of the neoplastic volume and the subpopulation of residual pancreatic cancer stem cells, improving the survival of patients with pancreatic cancer and decreasing the recurrence of the disease.

Methods: A pilot study is performed with the first ten patients in the experimental group. A randomized study (phase II-III clinical trial) that requires a population of 42 patients, with 21 patients in each group. All patients have a diagnosis of ductal adenocarcinoma of the pancreas, which will be surgically resected with curative intention. (I) Group I: after an R0 resection, patients receive individualized adjuvant treatments. (II) Group II: after an R0 resection, HIPEC is performed with gemcitabine (120 mg/m² for $30 \mathrm{~min}$ ), and they also receive individualized adjuvant treatments. To analyze the safety of the procedure, the main variables measured were as follows: grades of complications by means of the Clavien-Dindo system: pancreas surgery complications (e.g., pancreatic fistula, perioperative hemorrhage, delayed gastric emptying, biliary fistula), operative mortality, and laboratory parameters to control system functions. Values were measured three times: preoperatively, twenty-four hours after surgery, and on the 7 th postoperative day.

Results: From 2018 to 2019, 31 patients were recruited for our clinical trial. Fifteen patients were excluded because of intraoperative unresectability or a different intraoperative histologic diagnosis. Ten patients were included in the experimental group (resection plus HIPEC gemcitabine). The mean age was $65 \pm 7$ years, and six patients were female (60\%). We confirmed the histologic diagnosis of ductal pancreatic adenocarcinoma in all patients prior to HIPEC. Total pancreatectomy was performed in five patients. The surgical median time was $360 \mathrm{~min}$, and the hospital stay was 11 days. Four patients showed complications classified as 
Clavien-Dindo type II and one showing type I. Six patients were classified as having stage III tumors. To date, no hospital mortality, locoregional recurrence, or differences between the two groups in terms of perioperative complications, biochemical and gasometric values, or Clavien-Dindo complication grades were observed.

Conclusions: Our clinical pilot study demonstrated a similar perioperative outcome that allows the trial until main objectives are achieved.

Keywords: Pancreatic adenocarcinoma; hyperthermic intraperitoneal chemotherapy (HIPEC); chemohyperthermia; gemcitabine; cancer stem cells (CSCs)

Submitted Jun 28, 2020. Accepted for publication Oct 23, 2020.

doi: 10.21037/jgo-20-238

View this article at: http://dx.doi.org/10.21037/jgo-20-238

\section{Introduction}

Despite therapeutic advances, pancreatic adenocarcinoma continuously presents poor prognosis and constitutes the fourth leading cause of cancer mortality, with a high percentage of deaths in the United States (1-6). One characteristic of this disease is a prominent capacity for locoregional invasion resulting in increased local recurrence and therefore increased patient mortality. Recently, a population of pancreatic stem cells with the capacity of malignant transformation presenting a high rate of selfrenewal, a high expression of signaling molecule development (SHH or the Sonic hedgehog gene), and a great ability to develop variable cell subtypes has been identified (7-19).

Pancreatic adenocarcinoma stem cells are extremely resistant to chemotherapeutic drugs. In contact with such drugs, these tumor cells do not proliferate, remaining in a dormant stage. After the completion of chemotherapy, these cells resume great proliferative activity, allowing recurrence. In order to eliminate the early locoregional tumor invasion of pancreatic stem cells, we have developed a new therapeutic model, characterized by the application of hyperthermic intraperitoneal chemotherapy (HIPEC) with gemcitabine. The goal is to eliminate these locoregional stem cells and improve the prognosis of pancreatic cancer. The results after using HIPEC have been studied in several experimental models of peritoneal carcinomatosis and have been translated to the clinical practice with different chemotherapy drugs, obtaining promising results (19-30). These results encouraged our group to initiate this project to determine how gemcitabine acts locally combined with hyperthermia against pancreatic cancer.

Our project is a prospective randomized clinical trial that will include forty-two patients with pancreatic adenocarcinoma who undergo surgery in our department.

In the first step, we perform a clinical pilot study to document the safety of this treatment. In the second step, we attempt to establish our hypothesis that HIPEC with gemcitabine can reduce the tumor progression of pancreatic cancer by reducing the neoplastic volume and the subpopulation of pancreatic cancer stem cells (CSCs) and thereby improving overall survival.

Our first objective is to analyze perioperative morbidity and mortality associated with cytoreductive surgery and HIPEC with gemcitabine in comparison to a conventional treatment group without HIPEC. Secondly, we identify the overall survival and disease-free survival of the experimental group in a short-term follow-up with respect to the conventional group. Lastly, we attempt to identify, create, and cultivate pancreatic CSCs that are isolated during and after pancreatic cancer resection with HIPEC, performed during this trial. We present the following article in accordance with the CONSORT reporting checklist (available at http://dx.doi.org/10.21037/jgo-20-238).

\section{Methods}

This is a pilot study of a randomized phase II-III clinical trial and is open to the incorporation of other centers that could increase the power of the results. The study was conducted in accordance with the Declaration of Helsinki (as revised in 2013). The study was approved by the Clinical Research Ethics Committee of the University General Hospital, Ciudad Real institutional board (A-275, V6,20-72020) and informed consent was taken from all individual participants. 


\section{Population}

According to the incidence in the University General Hospital of Ciudad Real (HGUCR) and accepting an alpha risk of 0.05 and a beta risk of 0.2 , in a bilateral comparison, we include a population of 42 patients ( 21 patients in each group) diagnosed with ductal adenocarcinoma of the pancreas, which will be resected with curative intention from 2017 to 2021. For the survival study, there is an extended follow-up for at least 2 years. This study has been performed in two steps. In the first step (pilot phase), we treat the first ten patients in the experimental group (group II).

* Group I: after an R0 resection and after a multidisciplinary presentation, patients will receive an individualized adjuvant treatment;

* Group II: after R0 resection, HIPEC is performed with gemcitabine $\left(120 \mathrm{mg} / \mathrm{m}^{2}\right.$ for $\left.30 \mathrm{~min}\right)$, and an individualized adjuvant treatment is considered.

After explaining the treatment and informing the patient of the characteristics of pancreatic cancer, we obtain their informed consent and perform the randomization.

\section{Exclusion criteria}

* Voluntary refusal to participate in the trial;

* Existence of distant disease;

* Patients with neoadjuvant treatment;

* Patients with preoperative or intraoperative locoregional unresectable pancreatic cancer;

* Existence of synchronous neoplastic disease;

* Other histological subtypes of pancreatic cancer not diagnosed as pancreatic adenocarcinoma.

\section{Data collection}

* Main outcomes of clinical trial (overall survival, recurrence, disease-free survival, mortality);

* Main and secondary variables of the pilot study:

- Classification of Clavien-Dindo used for grading complications;

- Pancreatic surgical complications (e.g., pancreatic fistula, hemorrhage, delayed gastric emptying, biliary fistula);

- Operative mortality (within 30 days of the procedure);

- Clinical and surgical variables (age, sex, diabetes, dyslipidemia, arterial hypertension, symptomatology, surgical treatment, operative time, hospital stay, intraoperative transfusion);

- Histological variables [tumor diameter, tumor grade (G1, G2, G3), neural invasion, vascular invasion, lymphatic invasion, pathologic nodes];

- Biochemical and gasometric parameters to measure system functions (values are measured three times-preoperatively, 24 hours after surgery, and on the 7 th postoperative day);

- Renal system (urea, creatinine);

- Liver system [glutamic-oxalacetic transaminase (GOT), glutamic-pyruvic transaminase (GPT), bilirubin (BB)];

- Blood system [leukocytes, platelets, red blood cells, hemoglobin $(\mathrm{Hb})$, hematocrit (Hct)];

- $\mathrm{PO}_{2}, \mathrm{PCO}_{2}, \mathrm{HCO}_{3}, \mathrm{pH}$, lactic acid, prothrombin time, thromboplastin activity.

\section{Surgery}

A bilateral subcostal laparotomy was performed. After an examination of the abdominal cavity to rule out liver metastases that would contraindicate the resection, we achieve a retroperitoneal access to the superior mesenteric artery (SMA). There is a mobilization of the liver colonic angle with an extensive Kocher maneuver which allows us to expose the retroperitoneum and elevate duodenum and pancreas head to expose the great vessels. An interaortocaval lymphadenectomy is performed. The origin of the SMA is identified. If over $50 \%$ of the circumference of the celiac trunk or SMA plus occlusion of the superior mesenteric vein confluence or portal vein is seen, this would contraindicate the surgical resection. According to the location and characteristics of the primary pancreatic adenocarcinoma, we perform cephalic pancreaticoduodenectomy, total pancreatectomy, distal pancreatectomy, or non-anatomic pancreatectomy.

\section{HIPEC}

Once a definitive intraoperative histologic diagnosis of pancreatic adenocarcinoma is made, we use a closed HIPEC system with $\mathrm{CO}_{2}$ recirculation (PRS Combat ${ }^{\circledR}$ ). This model is composed of one pump and an external heater for the carrier solution. The system includes a gas exchanger that allows us to control the filling of the drug solution in the abdominal cavity and the output of the $\mathrm{CO}_{2}$ that is used to create turbulence for proper drug distribution. During the recirculation of the drug, gemcitabine $\left(120 \mathrm{mg} / \mathrm{m}^{2}\right.$ for $30 \mathrm{~min}), \mathrm{CO}_{2}$ will generate a turbulence with a dose of 0.6 to 

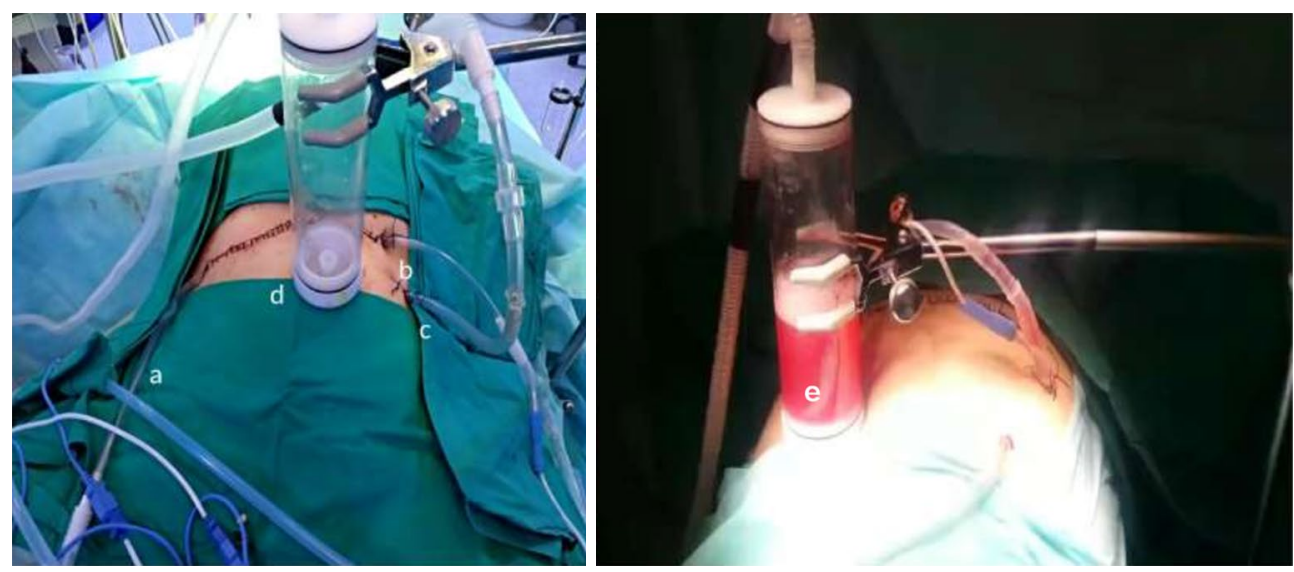

Figure 1 Closed hyperthermic intraperitoneal chemotherapy (HIPEC) technique with $\mathrm{CO}_{2}$ turbulence. a: Inflow catheter to fill the abdomen with solution; b: outflow catheter to remove the fluids into the HIPEC machine; c: inflow catheter to generate the turbulence with $\mathrm{CO}_{2}$; d: gas exchanger to control intrabdominal pressure and determine when the abdominal cavity is filled; e: during the recirculation of the drug, the gas exchanger allows the $\mathrm{CO}_{2}$ to be extracted and the intrabdominal pressure to be controlled.

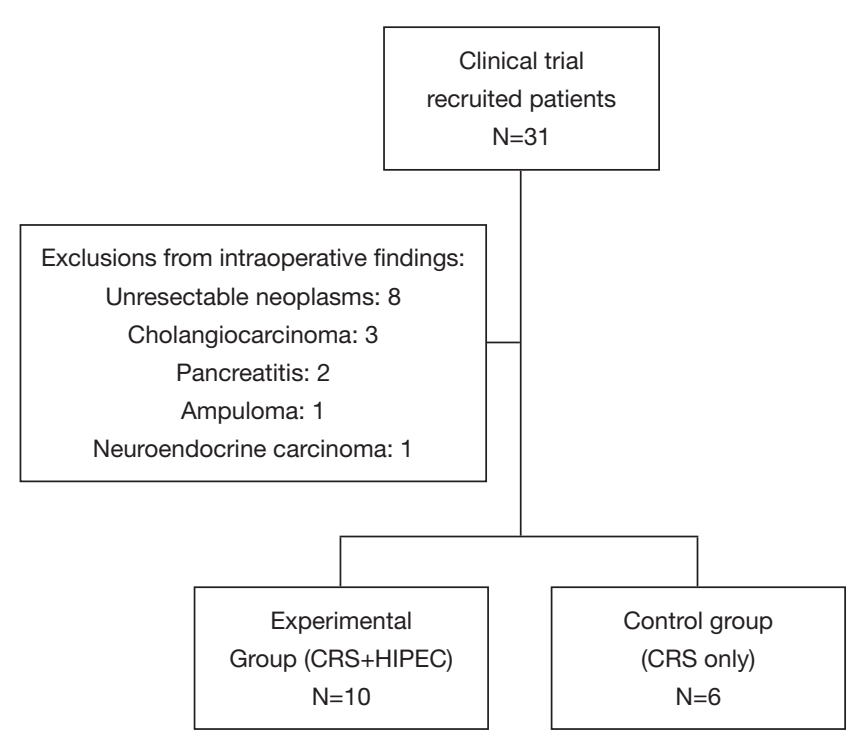

Figure 2 Patients recruited since 2018 in the clinical trial, and the causes for which some patients were excluded.

$0.7 \mathrm{~L} / \mathrm{min}$ and with controlled pressures (up to $15 \mathrm{mmHg}$ ). The $\mathrm{CO}_{2}$ used is sucked from the abdominal cavity through the gas exchanger. The dilution solution that we used during HIPEC was Physioneal 40, a peritoneal dialysis solution (Figure 1).

\section{Gemcitabine}

Gemcitabine is a drug that is metabolized intracellularly by nucleoside kinases to be transformed into active diphosphate nucleosides ( $\mathrm{dFdCDP}$ ) and triphosphate (dFdCTP). Gemcitabine will become active in the cellular phase, inhibiting cells that synthesize DNA and, under certain conditions, blocking the progression of cells G1 to S.

\section{Statistical analysis}

We have obtained frequency distributions for qualitative and quantitative variables. The continuous variables were expressed by mean, median, and standard deviation and were compared with the Student's or Mann-Whitney test. The correlations among the different parameters were analyzed using the Pearson correlation method. The survival study was realized by logistic regression models and the study of survival curves by the Kaplan-Meier method. For statistical analysis, we used SPSS $19.0^{\circledR}$. We considered a significant difference with $\mathrm{P}$ values $<0.05$.

\section{Results}

In 2018 and 2019, 31 patients with high suspicion of resectable pancreatic adenocarcinoma were recruited for our clinical trial. Fifteen patients were excluded because of intraoperative unresectability from locoregional invasion or an intraoperative diagnosis different from pancreatic adenocarcinoma (Figure 2). All the patients signed the consent form. Ten patients were included in the experimental group. The mean age was $65 \pm 7$ years, and six patients were female $(60.0 \%)$. All the characteristics of the 
Table 1 Clinical, surgical and histological characteristics of patients

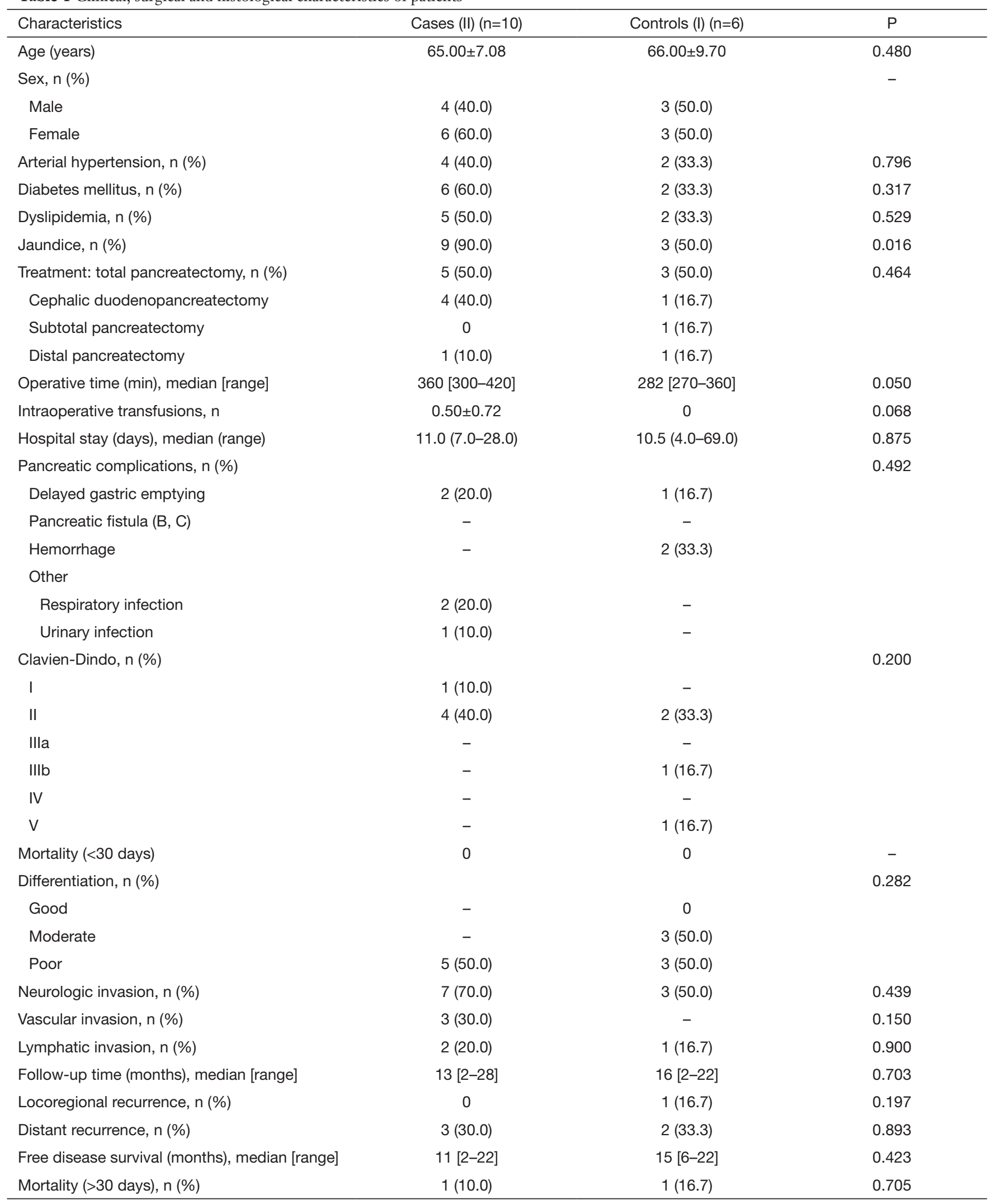


patients are listed in Table 1. We confirmed the histologic diagnosis of ductal pancreatic adenocarcinoma in all patients prior to resection plus HIPEC gemcitabine. Total pancreatectomy was performed in five patients and cephalic duodenopancreatectomy in four. The median time required for surgery was 360 minutes, and the hospital stay was 11 days. In terms of grading perioperative complications, four patients showed complications classified as ClavienDindo type II, one showing type I. Six patients were classified as having stage III tumors. No hospital mortality was observed. Six patients received adjuvant treatment: two patients received adjuvant gemcitabine, two were treated with capecitabine, and two treated with gemcitabine and paclitaxel. No locoregional recurrence was observed, and two patients showed hepatic metastasis at 28 and 18 months, respectively. No differences in perioperative complications by the Clavien-Dindo grades between the experimental group II and the group I without HIPEC were found. Mortality occurred in one patient 16 months after discharge. The biochemical and gasometric parameters preoperatively, at 24 hours after surgery and at 7 days were not different between group I and group II (Table 2).

\section{Discussion}

Pancreatic cancer has poor prognosis and a high mortality rate because of an unfavorable anatomic location of the primary adenocarcinoma plus an acquired drug resistance, leading to local and/or metastatic recurrence. It is the fourth leading cause of cancer-related deaths in Western countries. At the time of diagnosis, $80 \%$ of patients already have extensive diseases because of locoregional involvement (30-40\%) or distant metastases $(50 \%)$, so only $20 \%$ of patients have potentially curative surgical options. In spite of new surgical techniques and chemotherapeutic therapies, the 5 -year overall survival rate occurs in less than $6 \%$ of patients, and surgical resection is the only potentially curative treatment. Some mechanisms of drug resistance in primary tumor and peritoneal metastasis are CSCs, epithelial-mesenchymal transition (EMT), EMT-type cells, and the tumor microenvironment. CSCs play the main role in cancer invasion, recurrence, metastasis, and drug resistance because these cells have the ability to self-renew and may result in tumorigenesis. During EMT, epithelial cells such as CSCs, which habitually interact with the basal membrane, acquire a mesenchymal cell phenotype, and EMT-type cells and anomalous signaling pathways are altered (e.g., Sonic hedgehog, Notch, and Wnt signaling pathways) (12-19).

These stem cells can be located in the peritoneum during the surgical procedure, or they may detach from the tumor and not be resected. Peritoneal carcinomatosis may be the manifestation of a locoregional early stage, which can remain stable in the abdominal cavity during a predistant spread of disease. We think that if we intensify the locoregional treatment in pancreatic cancer using radical surgery and an adjuvant perioperative treatment with HIPEC, we may eradicate both the macroscopic disease and the microscopic residual disease. The additional use of hyperthermia with intraperitoneal locoregional chemotherapy causes a direct "toxic shock" on tumor cells and also promotes the penetration of cytotoxic drugs in tissues.

HIPEC has been studied in several experimental models of peritoneal metastases, which have obtained promising results in reducing the disease. Gemcitabine has been included in these peritoneal models to determine its pharmacokinetic behavior because its molecular weight allows for longer exposure, developing a greater intrabdominal cytotoxic activity with a minor systemic toxicity. Morgan et al. (26) developed a phase I study to identify the tolerated dose, toxicity, and pharmacokinetics characteristics of gemcitabine, but they included patients with peritoneal carcinomatosis from different origins, not only pancreatic cancer. They recommended using gemcitabine at $120 \mathrm{mg} / \mathrm{m}^{2}$.

In 2008, Gamblin et al. (27) included nine patients with unresectable pancreatic adenocarcinoma, with doses of $200 \mathrm{mg} / \mathrm{m}^{2}$ every twenty-four hours with good tolerance. Tentes et al. (30) also used gemcitabine in patients with pancreatic cancer and peritoneal metastasis. The small number of patients and different doses of gemcitabine do not allow us to obtain conclusions. The Washington Cancer Institute $(31,32)$ presented the initial results of a phase II study on the administration of adjuvant intraperitoneal gemcitabine in seven patients with resectable pancreatic adenocarcinoma. They were chosen patients with localized cancer in the head and/or tail of the pancreas, in which they could macroscopically carry out a curative resection. After surgery, HIPEC gemcitabine was instilled $\left(1,000 \mathrm{mg} / \mathrm{m}^{2}\right)$ into the peritoneal cavity using a peritoneal dialysis solution of $1.5 \%$ dextrose. The procedure lasted a total of $60 \mathrm{~min}$ with the open technique. Before closing the abdominal incision, they placed a Port-A-Cath in the abdominal cavity for the administration of six cycles of intraperitoneal gemcitabine at a dose of $1,000 \mathrm{mg} / \mathrm{m}^{2}$ 
Table 2 Biochemical and gasometric parameters between groups

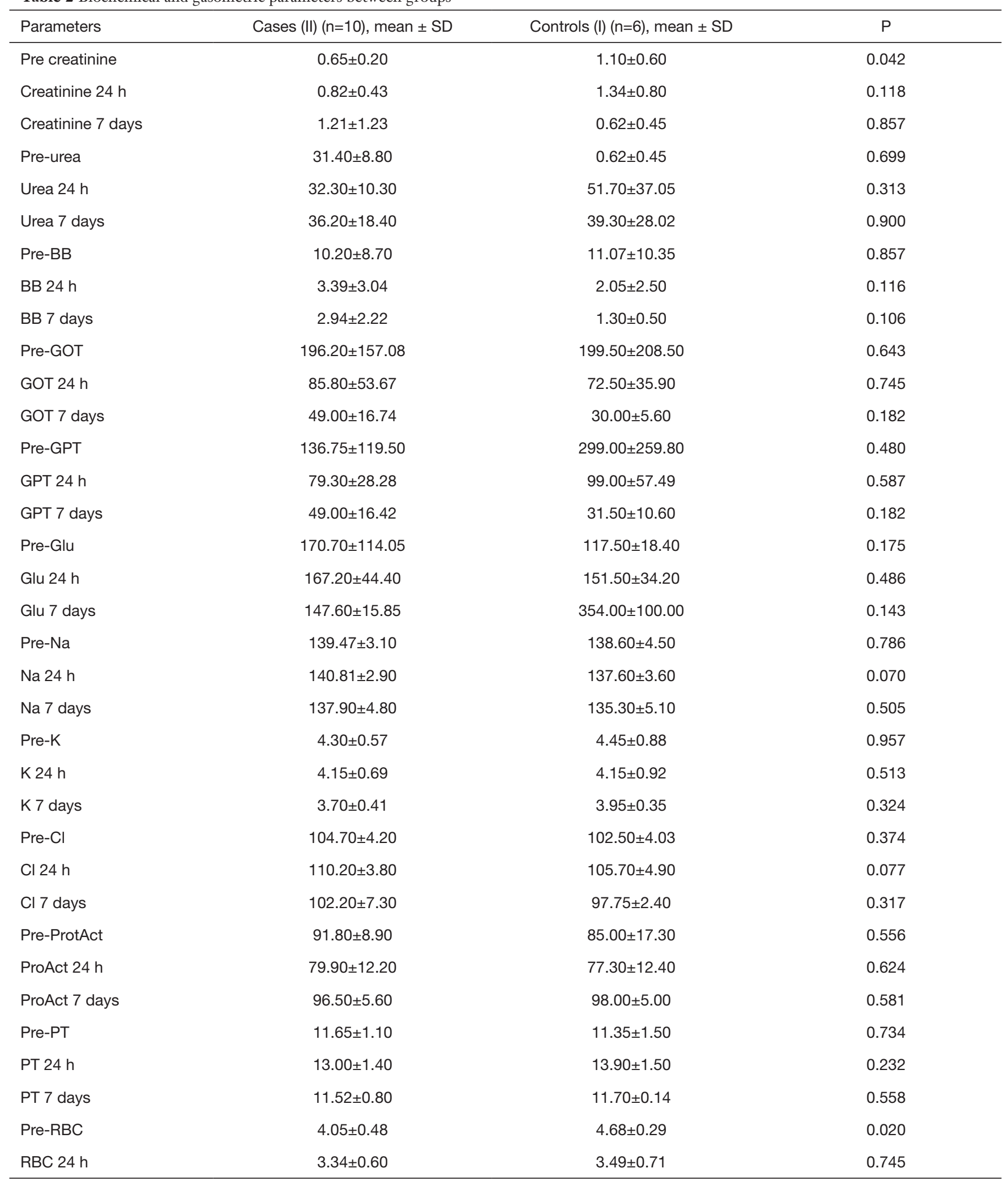

Table 2 (continued) 
Table 2 (continued)

\begin{tabular}{|c|c|c|c|}
\hline Parameters & Cases $(I I)(n=10)$, mean $\pm S D$ & Controls $(I)(n=6)$, mean \pm SD & $\mathrm{P}$ \\
\hline Pre-Pla & $362.480 \pm 104.600$ & $277.170 \pm 98.258$ & 0.664 \\
\hline Pla $24 \mathrm{~h}$ & $237.100 \pm 82.880$ & $243.170 \pm 79.903$ & 0.768 \\
\hline Pla 7 days & $271.000 \pm 106.829$ & $298.500 \pm 108.187$ & 0.739 \\
\hline Le $24 \mathrm{~h}$ & $14.040 \pm 5.300$ & $16.679 \pm 3.900$ & 0.516 \\
\hline Le 7 days & $14.400 \pm 5.600$ & $15.500 \pm 7.566$ & 0.900 \\
\hline Pre-Hb & $12.21 \pm 1.60$ & $13.30 \pm 2.20$ & 0.175 \\
\hline $\mathrm{Hb} 24 \mathrm{~h}$ & $10.20 \pm 1.60$ & $14.60 \pm 1.60$ & 0.739 \\
\hline Hct $24 \mathrm{~h}$ & $29.89 \pm 4.90$ & $32.50 \pm 5.50$ & 0.270 \\
\hline Hct 7 days & $28.80 \pm 4.90$ & $27.90 \pm 7.07$ & 0.739 \\
\hline Pre-PO 2 & $85.00 \pm 10.00$ & $86.00 \pm 20.00$ & 0.500 \\
\hline $\mathrm{PO}_{2} 24 \mathrm{~h}$ & $123.10 \pm 41.70$ & $126.80 \pm 26.06$ & 0.814 \\
\hline $\mathrm{PO}_{2} 7$ days & $84.00 \pm 9.80$ & $87.00 \pm 24.04$ & 0.121 \\
\hline Pre-PCO 2 & $43.00 \pm 7.07$ & $41.00 \pm 10.00$ & 0.800 \\
\hline $\mathrm{PCO}_{2} 24 \mathrm{~h}$ & $35.90 \pm 9.30$ & $42.67 \pm 6.70$ & 0.051 \\
\hline $\mathrm{PCO}_{2} 7$ days & $45.00 \pm 4.50$ & $46.50 \pm 3.50$ & 0.767 \\
\hline $\mathrm{HCO}_{3} 7$ days & $27.65 \pm 4.70$ & $34.65 \pm 10.67$ & 0.439 \\
\hline Pre-lactic acid & $9.67 \pm 4.50$ & $8.00 \pm 1.20$ & 0.550 \\
\hline Lactic acid $24 \mathrm{~h}$ & $28.30 \pm 23.06$ & $16.33 \pm 7.50$ & 0.175 \\
\hline Lactic acid 7 days & $11.50 \pm 3.50$ & $17.50 \pm 12.02$ & 0.683 \\
\hline
\end{tabular}

BB, bilirubin; GOT, glutamic-oxalacetic transaminase; GPT, glutamic-pyruvic transaminase; Glu, glucose; ProAct, prothrombin activity; PT, prothrombin time; RBC, red blood cell; Pla, platelets; Le, leukocytes; Hb, hemoglobin; Hct, hematocrit; SD, standard deviation.

beginning 4 to 6 weeks after surgery. The authors concluded that intraperitoneal administration of the drug was well tolerated, with no documented complications.

Tentes et al. $(33,34)$ identified the benefits of HIPEC with gemcitabine in patients who underwent complete tumor resection for pancreatic cancer. Twenty-one patients with resectable pancreatic cancer were chosen. They also included patients with limited macroscopic peritoneal metastasis and R1 cytoreductive surgery. After tumor resection, HIPEC was performed by the open "Coliseum" technique for 60 minutes at a temperature of $42-43{ }^{\circ} \mathrm{C}$ with gemcitabine at a dose of $1,000 \mathrm{mg} / \mathrm{m}^{2}$. The authors 
concluded that using HIPEC with gemcitabine reduced locoregional recurrence and could be considered as a safe and effective adjuvant therapy in pancreatic cancer.

Given the different doses of gemcitabine described in the medical literature and the identification of CD133-CX34 CSCs, we created an experimental model to identify the toxicity and efficacy of HIPEC with gemcitabine at doses recommended by Morgan et al. In this experimental model, the application of HIPEC with gemcitabine was possible for $30 \mathrm{~min}$ at $41-42{ }^{\circ} \mathrm{C}$ by the closed technique. No technical complications were observed during administration. With the development of this model, a significant reduction in pancreatic tumor stem cells $\mathrm{CD} 133^{+} \mathrm{CXCR} 4^{+}$and tumor volume was obtained (35).

After these results, we transported our model to practice by means of a clinical trial to homogenize the methods. We are the only group to use a closed HIPEC method with $\mathrm{CO}_{2}$ agitation to treat pancreatic cancer. The closed technique increases the tissue penetration of chemotherapy, reduces heat loss, and reduces the contamination risk for surgical staff. However, controversy exists regarding the effectiveness of the distribution of drugs and the possibility of an increase of abdominal pressure, which can affect cardiac preload. In addition, there are hemodynamic complications caused by the maintenance of hyperthermia.

For the first problem, we created a $\mathrm{CO}_{2}$ recirculation system that agitates the hyperthermic drug solution to reach all intraperitoneal areas. We demonstrated intraperitoneal temperature homogeneity with a thermographic analysis. For the second problem, the increase of abdominal pressure in a HIPEC closed system, our group considered that this morbidity could increase after using $\mathrm{CO}_{2}$ to create turbulence during HIPEC to achieve better drug distribution. However, we have demonstrated in the experimental models and clinical pilot study that using a closed HIPEC technique with $\mathrm{CO}_{2}$ recirculation, even with a laparoscopic approach, after performing cytoreductive surgery for peritoneal metastases is possible and safe, with an efficacy equal to that of conventional methods (34-40).

Resectable pancreatic cancer surgery leads to great perioperative morbidity. This could be greater if we add HIPEC. The results of our clinical pilot study demonstrate a similar perioperative outcome that allows us to continue with the trial until we can identify its main objectives. In our results, we found no significant differences between the experimental group and the control group with respect to perioperative values about the liver system, renal system, blood system, and metabolic and gasometric systems. The operating room surgical time was higher $(\mathrm{P}=0.050)$ with respect to the control group. However, the hospital stay was similar. Complications grading by the Clavien-Dindo system and pancreatic complications were not significantly different with respect to those found in the group without HIPEC $(\mathrm{P}=0.200 ; \mathrm{P}=0.492)$.

Interestingly, no local recurrence was observed, but two patients showed liver metastasis in the follow-up. Perhaps the treatment with adjuvant HIPEC helps control locoregional disease, but the CSCs, after the epithelial mesenchymal transition, could reach the blood vessels, leading to occult systemic micrometastasis. In our clinical trial, we grow in a stem cell medium a post-HIPEC serum sample and a post-HIPEC intraperitoneal residual solution. The results of this research might confirm our hypothesis on the relationship between residual CSCs and poor prognosis in these patients. The isolation of these CSCs will lead us to identify a selective chemotherapy for each patient and lower the resistance of ineffective drugs.

In spite of our results, the limitations of the study include the short follow-up time to define conclusions with respect to disease-free survival or overall survival as well as the small population size. Unfortunately, the SARS-CoV-2 pandemic has paused the recruitment for months. This is an open phase II-III study, and other hospitals may contribute to patient accrual.

\section{Acknowledgments}

Funding: None.

\section{Footnote}

Provenance and Peer Review: This article was commissioned by the Guest Editors (Paul H. Sugarbaker and Kurt Van der Speeten) for the focused issue "Intraperitoneal Chemotherapy for Peritoneal Metastases: HIPEC, EPIC, NIPEC, PIPAC and More" published in Fournal of Gastrointestinal Oncology. This article has undergone external peer review.

Reporting Checklist: The authors have completed the CONSORT reporting checklist. Available at http://dx.doi. org/10.21037/jgo-20-238

Data Sharing Statement: Available at http://dx.doi. org/10.21037/jgo-20-238

Conflicts of Interest: All authors have completed the ICMJE 
uniform disclosure form (available at http://dx.doi. org/10.21037/jgo-20-238). The focused issue was sponsored by the Peritoneal Surface Oncology Group International (PSOGI). The authors have no other conflicts of interest to declare.

Ethical Statement: The authors are accountable for all aspects of the work in ensuring that questions related to the accuracy or integrity of any part of the work are appropriately investigated and resolved. The study was conducted in accordance with the Declaration of Helsinki (as revised in 2013). The study was approved by the Clinical Research Ethics Committee of the University General Hospital, Ciudad Real institutional board (A-275, V6,20-72020) and informed consent was taken from all individual participants.

Open Access Statement: This is an Open Access article distributed in accordance with the Creative Commons Attribution-NonCommercial-NoDerivs 4.0 International License (CC BY-NC-ND 4.0), which permits the noncommercial replication and distribution of the article with the strict proviso that no changes or edits are made and the original work is properly cited (including links to both the formal publication through the relevant DOI and the license). See: https://creativecommons.org/licenses/by-nc-nd/4.0/.

\section{References}

1. Jemal A, Siegel R, Ward E, et al. Cancer statistics 2008. CA Cancer J Clin 2008;58:71-96.

2. Navarro S, Vaquero E, Maurel J, et al. Recomendaciones para el diagnóstico, estadificación y tratamiento del cáncer de páncreas (parte II) Recommendations for diagnosis, staging and treatment of pancreatic cancer (Part II). Med Clin (Barc) 2010;134:692-702.

3. Hermann PC, Huber SL, Herrler T, et al. Distinct populations of cancer stem cells determine tumor growth and metastatic activity in human pancreatic cancer. Cell Stem Cell 2007;1:313-23.

4. Hezel AF, Kimmelman AC, Stanger BZ, et al. Genetics and biology of pancreatic ductal adenocarcinoma. Genes Dev 2006;20:1218-49.

5. Muniraj T, Jamidar PA, Aslanian HR. Pancreatic cancer: a comprehensive review and update. Dis Mon 2013;59:368-402.

6. Ansari D, Chen BC, Dong L, et al. Pancreatic cancer: translational research aspects and clinical implications.
World J Gastroenterol 2012;18:1417-24.

7. Bardeesy N, De Pinho RA. Pancreatic cancer biology and genetics. Nat Rev Cancer 2002;2:897-909.

8. Mungamuri SK, Yang X, Thor AD, et al. Survival signaling by Notch1: mammalian target of rapamycin (mTOR)dependent inhibition of p53. Cancer Res 2006;66:4715-24.

9. Ischenko I, Seeliger H, Kleespies A, et al. Pancreatic cancer stem cells: new understanding of tumorigenesis, clinical implications. Langenbecks Arch Surg 2010;395:1-10.

10. Reya T, Morrison SJ, Clarke MF, et al. Stem cells, cancer, and cancer stem cells. Nature 2001;414:105-11.

11. Clarke MF, Dick JE, Dirks PB, et al. Cancer stem cellsperspectives on current status and future directions: AACR workshop on cancer stem cells. Cancer Res 2006;66:9339-44.

12. Dean M, Fojo T, Bates S. Tumour stem cells and drug resistance. Nat Rev Cancer 2005;5:275-84.

13. Wu XZ. Origin of Cancer Stem Cells: The Role of Self-Renewal and Differentiation. Ann Surg Oncol 2008;15:407-14.

14. Reguart N, He B, Taron M, et al. The role of Wnt signaling in cancer and stem cells. Future Oncol 2005;1:787-97.

15. Taipale J, Beachy PA. The Hedgehog and Wnt signaling pathways in cancer. Nature 2001;411:349-54.

16. Li C, Heidt DG, Dalerba P, et al. Pancreatic Cancer Stem Cells. Cancer Res 2007;67:1030-7.

17. Moriyama T, Ohuchida K, Mizumoto K, et al. Enhanced Cell Migration and Invasion of CD133 Pancreatic Cancer Cells Cocultured With Pancreatic Stromal Cells. Cancer 2010;116:3357-68.

18. Liao WC, Wang HP, Huang HY, et al. CXCR4 Expression Predicts Early Liver Recurrence and Poor Survival After Resection of Pancreatic Adenocarcinoma. Clin Transl Gastroenterol 2012;3:e22.

19. Marchesi F, Monti P, Leone BE, et al. Increased survival, proliferation, and migration in metastatic human pancreatic tumor cells expressing functional CXCR4. Cancer Res 2004;64:8420-7.

20. Glehen O, Mohamed F, Gilly FN. Peritoneal carcinomatosis from digestive tract cancer: new management by cytoreductive surgery and intraperitoneal chemohyperthermia. Lancet Oncol 2004;5:219-28.

21. Chua TC, Yan TD, Saxena A, et al. Should the treatment of peritoneal carcinomatosis by cytoreductive surgery and hyperthermic intraperitoneal chemotherapy still be regarded as a highly morbid procedure?: a systematic review of morbidity and mortality. Ann Surg 2009;249:900-7.

22. Roviello F, Caruso S, Marrelli D, et al. Treatment of 
peritoneal carcinomatosis with cytoreductive surgery and hyperthermic intraperitoneal chemotherapy: state of the art and future developments. Surg Oncol 2011;20:e38-54.

23. Sugarbaker PH. Surgical management of peritoneal carcinosis: diagnosis, prevention and treatment. Langenbecks Arch Chir 1988;373:189-96.

24. Pelz JOW, Doerfer J, Dimmler A, et al. Histological response of peritoneal carcinomatosis after hyperthermic intraperitoneal chemoperfusion (HIPEC) in experimental investigations. BMC Cancer 2006;6:162.

25. Pestieau SR, Schnake KJ, Stuart OA, et al. Impact of carrier solutions on pharmacokinetics of intraperitoneal chemotherapy. Cancer Chemother Pharmacol 2001;47:269-76.

26. Morgan RJ, Synold TW, Xi B, et al. Phase I Trial of intraperitoneal gemcitabine in the treatment of advanced malignancies primarily confined to the peritoneal cavity. Clin Cancer Res 2007;13:1232-7.

27. Gamblin TC, Egorin MJ, Zuhowski EG, et al. Intraperitoneal gemcitabine pharmacokinetics: a pilot and pharmacokinetic study in patients with advanced adenocarcinoma of the pancreas. Cancer Chemother Pharmacol 2008;62:647-53.

28. Burris HA 3rd, Moore MJ, Andersen J, et al. Improvements in survival and clinical benefit with gemcitabine as firstline therapy for patients with advanced pancreas cancer: a randomized trial. J Clin Oncol 1997;15:2403-13.

29. Ridwelski K, Meyer F, Hribaschek A, et al. Intraoperative and early postoperative chemotherapy into the abdominal cavity using gemcitabine may prevent postoperative occurrence of peritoneal carcinomatosis. J Surg Oncol 2002;79:10-6.

30. Tentes AA, Pallas N, Karamveri C, et al. Cytoreduction and HIPEC for peritoneal carcinomatosis of pancreatic cancer. J BUON 2018;23:482-7.

31. Kamath A, Yoo D, Stuart OA, et al. Rationale for an intraperitoneal gemcitabine chemotherapy treatment for patients with resected pancreatic cancer. Recent Pat Anticancer Drug Discov 2009;4:174-9.

32. Sugarbaker PH, Stuart OA, Bijelic L. Intraperitoneal gemcitabine chemotherapy treatment for patients with resected pancreatic cancer: rationale and report of early data. Int J Surg Oncol 2011;2011:161862.

33. Tentes AA, Kyziridis D, Kakolyris S, et al. Preliminary results of hyperthermic intraperitoneal intraoperative chemotherapy as an adjuvant in resectable pancreatic cancer. Gastroenterol Res Pract 2012;2012:506571.

34. Tentes AA, Stamou K, Pallas N, et al. The effect of hyperthermic intraoperative intraperitoneal chemotherapy (HIPEC) as an adjuvant in patients with resectable pancreatic cancer. Int J Hyperthermia 2016;32:895-9.

35. García-Santos EP, Padilla-Valverde D, Villarejo-Campos $\mathrm{P}$, et al. The utility of hyperthermic intra-abdominal chemotherapy with gemcitabine for the inhibition of tumor progression in an experimental model of pancreatic peritoneal carcinomatosis, in relation to their behavior with pancreatic cancer stem cells CD133+ CXCR4. Pancreatology 2016;16:632-9.

36. Sánchez-García S, Padilla-Valverde D, Villarejo-Campos $\mathrm{P}$, et al. Experimental development of an intra-abdominal chemohyperthermia model using a closed abdomen technique and a PRS-1.0 Combat CO2 recirculation system. Surgery 2014;155:719-25.

37. Sánchez-García S, Villarejo-Campos P, Padilla-Valverde $\mathrm{D}$, et al. Intraperitoneal chemotherapy hyperthermia (HIPEC) for peritoneal carcinomatosis of ovarian cancer origin by fluid and $\mathrm{CO} 2$ recirculation using the closed abdomen technique (PRS-1.0 Combat): A clinical pilot study. Int J Hyperthermia 2016;32:488-95.

38. Padilla-Valverde D, Sanchez-Garcia S, García-Santos

$\mathrm{E}$, et al. Usefulness of thermographic analysis to control temperature homogeneity in the development and implementation of a closed recirculating $\mathrm{CO} 2$ chemohyperthermia model. Int J Hyperthermia 2017;33:220-6.

39. Pascual-Ramírez J, Sánchez-García S, González-Ruiz de la Herrán F, et al. Security and efficiency of a closed-system, turbulent-flow circuit for hyperthermic intraperitoneal chemotherapy after cytoreductive ovarian surgery: perioperative outputs. Arch Gynecol Obstet 2014;290:121-9.

40. Sánchez-García S, Padilla-Valverde D, VillarejoCampos P, et al. Hyperthermic chemotherapy intraabdominal laparoscopic approach: development of a laparoscopic model using CO2 recirculation system and clinical translation in peritoneal carcinomatosis. Int $\mathrm{J}$ Hyperthermia 2017;33:684-9.

Cite this article as: Padilla-Valverde D, García-Santos E, Sanchez S, Manzanares C, Rodriguez M, González L, Ambrós A, Cano JM, Serrano L, Bodoque R, Vergara T, Martin J. Safety of perioperative hyperthermic intraperitoneal chemotherapy with gemcitabine in patients with resected pancreatic adenocarcinoma: a pilot study of the clinical trial EudraCT 2016-004298-41. J Gastrointest Oncol 2021;12(Suppl 1): S80-S90. doi: 10.21037/jgo-20-238 